Article

\title{
Corrosion Fatigue of Fine Grain Mg-Zn-Zr and Mg-Y-Zn Alloys
}

\author{
Mikhail Linderov ${ }^{1}$ (D), Evgenii Vasilev ${ }^{1}$, Dmitry Merson ${ }^{1}$, Mikhail Markushev ${ }^{2}$ and \\ Alexei Vinogradov ${ }^{1,3, *}$ \\ 1 Institute of Advanced Technologies, Togliatti State University, Togliatti 445020, Russia; \\ dartvi@gmail.com (M.L.); evg.vasilyev11@gmail.com (E.V.); D.Merson@tltsu.ru (D.M.) \\ 2 Institute for Metals Superplasticity Problems, Russian Academy of Sciences, Ufa 450001, Russia; \\ mvmark@imsp.ru \\ 3 Department of Mechanical and Industrial Engineering, Norwegian University of Science and \\ Technology-NTNU, N-7491 Trondheim, Norway \\ * Correspondence: alexei.vinogradov@ntnu.no; Tel.: +47-735-93769
}

Received: 29 November 2017; Accepted: 29 December 2017; Published: 31 December 2017

\begin{abstract}
Corrosion fatigue data for magnesium alloys are still scarce. The present communication reports the results of microstructural investigations and fatigue testing of the fine grain $\mathrm{Mg}-\mathrm{Zn}-\mathrm{Zr}$ (ZK60) alloy after multiaxial isothermal forging and of the hot extruded Mg-Y-Zn (WZ21) alloy in air and in the $0.9 \% \mathrm{NaCl}$ water solution. Both of the alloys demonstrate a very good high-cycle fatigue performance in air. However, the significant drop of fatigue resistance is observed in the corrosive environment. Results are discussed from perspectives of potential applications and future studies.
\end{abstract}

Keywords: magnesium alloys; fatigue properties; corrosion fatigue; severe plastic deformation; multiaxial isothermal forging

\section{Introduction}

Magnesium is the lightest structural metal. The exceptionally high specific strength renders magnesium alloys of much value for transportation engineering. Besides, in combination with natural biodegradability and low elastic moduli, the small weight and high strength make Mg-based alloys promising in bio-medical applications as orthopedic implants and cardiovascular stents. Many mechanical parts are often subjected to variable loading in an aggressive environment. When considering the high reactivity of magnesium and its alloys, it is of significant importance to assess their corrosion fatigue characteristics and to get a deeper insight into underlying corrosion fatigue mechanisms.

Experimental data on corrosion fatigue of magnesium alloys are still scarce. Furthermore, the vast majority of available to date data has been obtained on Al-containing alloys, which are admittedly the most widely used structural alloys due to their superior corrosion properties when compared with many other Mg-based alloys [1-6]. Regardless of different details in experimental conditions, the ubiquitous conclusion is that the high cycle fatigue performance reduces dramatically in chlorine-containing solutions. For example, Unigovski et al. [7] performed corrosion fatigue tests of extruded AZ31 and AZ91D and die-cast AM50 magnesium alloys in $\mathrm{NaCl}$ solutions, and found that the finer grain extruded alloys had significantly better fatigue properties both in air and in an aggressive environment in comparison to the coarse grain die-cast counterparts.

Hilpert and Wagner [8] characterized the corrosion fatigue behavior of the relatively high-strength alloy AZ80, with a focus on the effect of surface conditions on fatigue life. They noticed that while mechanical polishing and/or shot peening improved fatigue performance in air, no improvement was observed in $\mathrm{NaCl}$ solutions. 
The problem is particularly acute for alloys aimed at bio-medical applications [9]. When a bio-resorbable implant is placed in the body, its load-bearing capacity must remain until osteosynthesis is completed. Hence, besides static strength, corrosion, and stress corrosion cracking, corrosion fatigue should be thoroughly evaluated both in vitro and in vivo to ensure functionality and safety of Mg-based orthopedic devices. While the corrosion behavior of biomedical magnesium-based alloys has received considerable attention resulting in a large number of reports $[10,11]$, corrosion fatigue studies are still very limited [12]. Available studies, which are related to structural materials, are largely irrelevant for bio-medical applications, because, as has been mentioned above, the most popular engineering alloys included in many reports generally contain $\mathrm{Al}$ that is believed to be toxic to human. The detrimental effect of chlorine-containing solutions of fatigue performance of $\mathrm{Mg}$ alloys can be illustrated from the results by Gu et al. [13] who carried out corrosion fatigue studies on AZ91 and WE43 alloys in a simulated body fluid (SBF). These authors demonstrated that the conventional fatigue limit at $10^{7}$ cycles in the die-cast AZ91D reduced from of $50 \mathrm{MPa}$ in air to $20 \mathrm{MPa}$ at $10^{6}$ cycles tested in $\mathrm{SBF}$ at $37^{\circ} \mathrm{C}$. The higher strength alloy WE43 demonstrated the fatigue limit of $110 \mathrm{MPa}$ at $10^{7}$ cycles in the air, which dropped to $40 \mathrm{MPa}$ in SBF at the same number of cycles.

Over the recent years, a variety of severe plastic deformation (SPD) techniques has been developed for microstructure refinement and strengthening of metallic materials [14]. What is important is that not only the monotonic or fatigue strength can increase remarkably with grain refinement down to the sub-micrometer scale, but the resistance to general corrosion [15], and stress corrosion cracking [16] can also increase due to better homogeneity of the microstructure after SPD. In application to magnesium alloys, Aung et al. [17] have demonstrated quite convincingly that the corrosion rate reduced significantly with decreasing grain size. Vinogradov et al. [18] have shown that grain refinement through integrated SPD processing involving direct extrusion combined with two equal channel angular pressing passes is effective for improving the high cycle fatigue performance of the ZK60 alloy in parallel with enhanced tensile properties and galvanic corrosion resistance $[19,20]$. The potential of SPD techniques to synthesize novel materials with enhanced properties profile is particularly high for $\mathrm{Mg}$ alloys whose performance-both fatigue and corrosion-suffers from substantial inhomogeneity of the as-cast structure, which is difficult to get rid of in the course of conventional thermo-mechanical treatments.

Thus, the objective of the present work is to update the existing limited database of corrosion fatigue properties of $\mathrm{Mg}$ alloys through characterization of the fatigue behavior in ambient air and in the standard saline solution of two widespread alloys-Mg-Zn-Zr (ZK60) and Mg-Y-Zn (WZ21) - both considered as candidates for biomedical applications. The alloy ZK60 was processed by SPD via multiaxial isothermal forging for microstructure refinement.

\section{Materials and Methods}

All of the alloys were prepared by the conventional ingot casting process. The billets of the alloy ZK60 (nominal composition Mg-6Zn-0.5Zr, in wt.\%) with dimensions $70 \times 70 \times 170 \mathrm{~mm}^{3}$ were subjected to multi-axial isothermal forging (MIF) at $400{ }^{\circ} \mathrm{C}$ from a hot-pressed rod in the peak aged (T6) condition. On the second step, MIF was performed at $300^{\circ} \mathrm{C}$. During processing, the billet experienced six deformation cycles on each step involving a sequence of settings and drawings with axis changing, as described in [21,22]. The total true strain imparted on a working billet at the first step was of 4.2 and 3.0 at the second. The last deformation cycle at each step was ended by oil cooling. The hot extruded alloy WZ21 (Mg-2Y-1Zn-0.25Ca-0.15Mn nominal composition, in wt.\%) was considered as a representative of a class of rare earth element containing advanced $\mathrm{Mg}$ alloys, which is among other popular candidates for application as bio-resorbable implants and used for comparison.

The alloy microstructure was analyzed in the longitudinal plane of the billets in the field emission gun scanning electron microscope (SEM) Zeiss Sigma (Jena, Germany), equipped with the electron backscattering diffraction (EBSD) detector (EDAX/TSL) and orientation image microscopy (OIM) software package (OIM-6.2, EDAX/TSL, Mahwah, NJ, USA). Prior to microstructural analysis, 
the samples were mechanically polished to a mirror-like finish and then electrolytically polished in $90 \%$ ethanol $+10 \%$ nitric acid solution. The transmission electron microscope (TEM), JEOL JEM-2100-KY (Tokyo, Japan), operating at $200 \mathrm{kV}$ was used to examine the fine grain structure in some alloys. The thin foils for TEM observations were prepared by ion milling.

The specimens for mechanical testing were cut by spark erosion in the longitudinal direction of the worked billets. The uniaxial tensile tests were performed on the screw-driven testing machine under constant nominal strain rate of $1 \times 10^{-4} \mathrm{~s}^{-1}$.

Corrosion rate was measured by the gravimetric method, whereby metal coupons were exposed to the test medium (saline solution, which is commonly used in a wide variety of molecular and cellular biology applications) and measure the loss of weight of the material, as described in detail in [23]. The plate specimens with the surface area of $650-800 \mathrm{~mm}^{2}$ were ground by a sandpaper down to \#2500 grade, washed in the ultrasonic bath with acetone, dried, and weighted on the analytical balance with the accuracy of $0.0001 \mathrm{~g}$. They were then immersed in $0.9 \%$ sodium chloride $(\mathrm{NaCl})$ distilled water solution ( $\mathrm{pH}=7.4$ ) for $24 \mathrm{~h}$ at $25^{\circ} \mathrm{C}$ and following removal, the specimens were dried by hot air. The corrosion products were removed from the surface by the solution containing $200 \mathrm{~g}$ of $\mathrm{CrO}_{3}, 10 \mathrm{~g}$ of $\mathrm{AgNO}_{3}$ and $1000 \mathrm{~cm}^{3}$ of distilled water at $20-25^{\circ} \mathrm{C}$. The specimens were then immediately weighted again.

The miniature specimens with the cross-section area of $2 \times 2 \mathrm{~mm}^{2}$ and a gauge length of $5 \mathrm{~mm}$ were prepared for mechanical testing were prepared as described in [22]. The specimen surface was mechanically finished by a fine sandpaper with \#2000-grit. An Electropuls 1000 electro-mechanical testing machine (Instron, Norwood, MA, USA) operating in a symmetric push-pull cycling $(R=-1)$ mode at $100 \mathrm{~Hz}$ frequency was used for the tests at an ambient temperature in dry air and in the saline solution. Corrosion fatigue tests were carried out in a homemade thermostatic plastic bath filled with a freshly made $0.9 \% \mathrm{NaCl} /$ distilled water solution $(\mathrm{pH}=7.4)$ at temperature $37 \pm 1{ }^{\circ} \mathrm{C}$. The fatigue tests started immediately after submerging the specimen into the solution running at $0.1-0.7 \mathrm{~L} / \mathrm{min}$, and were performed in the stress-controlled mode at constant stress amplitudes $\Delta \sigma / 2$.

\section{Results and Discussion}

Typical EBSD OIM maps representing the grain structure of the alloys under investigation are shown in Figure 1. Corresponding SEM images in back-scattered electron (BSE) contrast are displayed in Figure 2. The alloy ZK60 after MIF exhibits partially recrystallized fine-grained microstructure. Since MIF has been performed at high (for magnesium) homologous temperature, the main mechanism of grain refinement is associated with dynamic recrystallization (DRX), giving rise to very fine equiaxed grains from 1 to $10 \mu \mathrm{m}$ size. However, since DRX has not been completed during the first step MIF processing at $400{ }^{\circ} \mathrm{C}$, it results in the very heterogeneous bi-modal grain structure consisting of fine recrystallized grains and coarse (several tens or even hundred micrometers size) initial grains embedded in the matrix of finer grains, Figures 1a and 2a. The microstructure after two-step MIF (at $400{ }^{\circ} \mathrm{C}+300^{\circ} \mathrm{C}$ ), Figures $1 \mathrm{~b}$ and $2 \mathrm{~b}$, is much more homogeneous. The grain structure of this alloy is relatively uniform. It comprises of fine, equiaxed grains with a volume fraction of $75 \%-80 \%$. The same can be said about the microstructure of the alloy WZ21. However, the grains are appreciably coarser than in the two-step MIF-processed ZK60 alloy. Grain size mean values that were obtained by the standard intercept method are shown in Table 1. Thus, considerable grain refinement occurred in the course of SPD as is reasonably expected. Besides, it has been found that the distribution of $\mathrm{Mg}-\mathrm{Zn}$ excess phases existing in the as-cast structure retains in the MIF-processed ZK60 billets, though the size of second phases is much smaller than in the as-cast state [23]. The microstructure of the alloy WZ21 is featured by the presence of the so-called long-period stacking ordered (LPSO) structure, which is typical of some Mg-Zn-RE alloys (e.g., Mg-Zn-Y) of specific chemical compositions [24,25]. Figure $2 \mathrm{c}$ reveals a relatively large fraction of second phases (primarily LPSO), aligned with extrusion direction in this multi-component alloy. The bright filed TEM image and the corresponding secondary electron diffraction pattern shown in Figure 3 illustrate the typical appearance of the LPSO phase in the alloy WZ21. 
Table 1. Properties of Mg alloys tested.

\begin{tabular}{|c|c|c|c|c|c|c|c|c|}
\hline \multirow{3}{*}{ Alloy } & \multirow{3}{*}{$\begin{array}{l}\text { Grain Size, } \\
\text { d }(\mu \mathrm{m})\end{array}$} & \multirow{3}{*}{$\begin{array}{c}\text { Corrosion Rate, } \\
(\mathrm{mm} / \text { year })\end{array}$} & \multicolumn{3}{|c|}{ Tensile Data } & \multicolumn{3}{|c|}{ Fatigue Data, $\sigma_{-1}, \mathrm{MPa}$} \\
\hline & & & \multirow{2}{*}{$\begin{array}{l}\sigma_{Y S} \\
\mathrm{MPa}\end{array}$} & \multirow{2}{*}{$\begin{array}{l}\sigma_{\text {UTS }} \\
\text { MPa }\end{array}$} & \multirow{2}{*}{$\delta, \%$} & \multicolumn{2}{|c|}{ Air } & \multirow{2}{*}{$\begin{array}{c}\mathrm{NaCl} \\
\mathrm{N}_{\mathrm{f}}=10^{6}\end{array}$} \\
\hline & & & & & & $N_{f}=10^{7}$ & $N_{f}=10^{6}$ & \\
\hline ZK60 hot pressed & $12.3 \pm 12$ & $4.6 \pm 0.9$ & 150 & 244 & 11 & $55 \pm 2$ & $65 \pm 3$ & $28 \pm 5$ \\
\hline ZK60 MIF $400{ }^{\circ} \mathrm{C}$ & $7.1 \pm 3.4$ & $3.3 \pm 1.4$ & 180 & 300 & 32 & $82 \pm 2$ & $92 \pm 2$ & $25 \pm 3$ \\
\hline $\begin{array}{c}\mathrm{ZK} 60 \mathrm{MIF} 400^{\circ} \mathrm{C} \\
+300^{\circ} \mathrm{C}\end{array}$ & $5.0 \pm 0.3$ & $2.6 \pm 0.5$ & 230 & 328 & 29 & $105 \pm 3$ & $105 \pm 3$ & $26 \pm 3$ \\
\hline WZ21 & $13.0 \pm 2.0$ & $1.6 \pm 0.2$ & 157 & 260 & 26 & $90 \pm 2$ & $95 \pm 3$ & $28 \pm 5$ \\
\hline
\end{tabular}

Magnesium alloys with the LPSO phase have attracted a great deal of attention in the last years, owing to their outstanding properties profile, including high mechanical strength, fatigue, and corrosion resistance [26]. A large hope has been fostered that these materials can boost bio-medical performance and applications by taking advantage of their high strength and low corrosion rate. Indeed, the results of the static corrosion tests show that the alloy WZ21 outperforms the alloy ZK60 in terms of general corrosion rate, Table 1 . Figure 4 shows the typical appearance of the corroded surface after holding the alloys in $0.9 \% \mathrm{NaCl}$ solution at $37^{\circ} \mathrm{C}$ for $24 \mathrm{~h}$. The figure highlights the difference between the ZK60 and WZ21 alloys, which is most clearly visible on SEM images. Figure $4 \mathrm{~b}$ reveals that the alloy ZK60 is prone to localized corrosion, which tends to form deep cracks on the surface, while uniform corrosion occurs predominantly in the alloy WZ21.
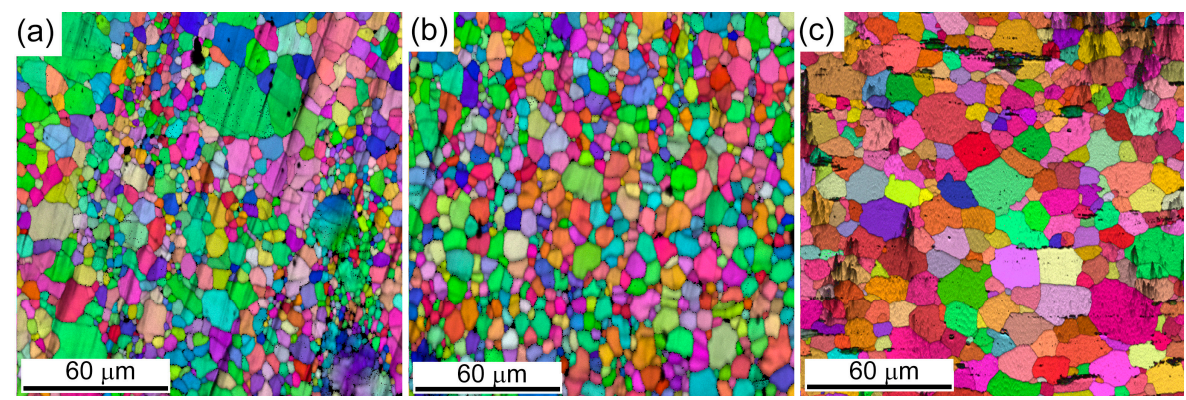

Figure 1. Electron backscattering diffraction (EBSD) maps of the longitudinal sections of the alloy ZK60 MIF-processed through one step at $400{ }^{\circ} \mathrm{C}$ (a) and two-steps at $400{ }^{\circ} \mathrm{C}$ and $300{ }^{\circ} \mathrm{C}$ (b), and (c) shows the grain structure of the hot extruded alloy WZ21.
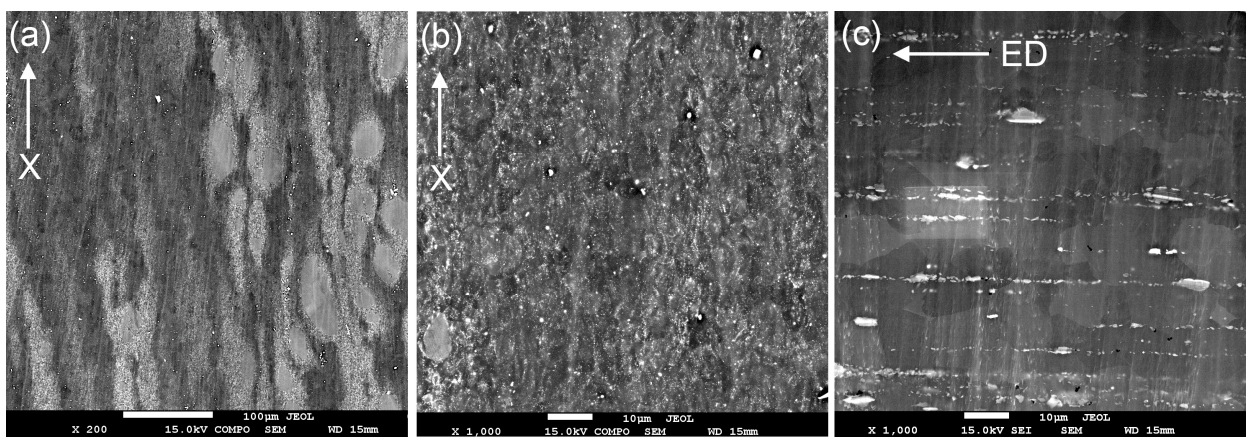

Figure 2. Scanning electron microscope (SEM) images showing the microstructure of the alloy ZK60 $(\mathbf{a}, \mathbf{b})$ and WZ21 (c) corresponding to the same specimens, as shown in Figure 1a,b-ZK60 MIF-processed through one step at $400{ }^{\circ} \mathrm{C}$ and two-steps at $400{ }^{\circ} \mathrm{C}$ and $300{ }^{\circ} \mathrm{C}$, respectively, and Figure $1 \mathrm{c}$ - the hot extruded alloy WZ21. Arrows indicate the working direction: $\mathrm{X}$ on $(\mathbf{a}, \mathbf{b})$ denotes the longitudinal direction of multi-axial isothermal forging (MIF) (see [27] for details) and ED on (c) corresponds to the extrusion direction. 


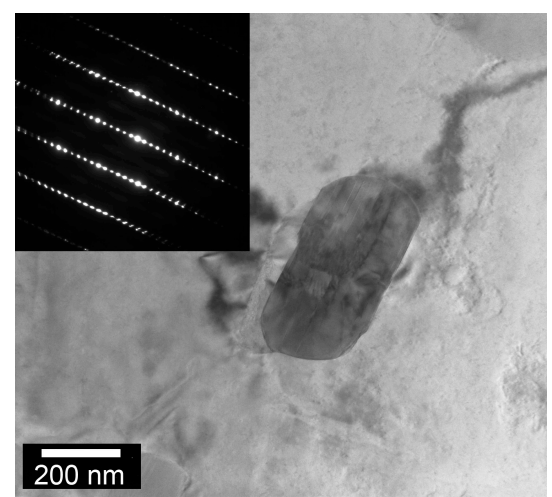

Figure 3. Typical bright filed TEM image and the selected area diffraction pattern illustrating the grain with the long-period stacking ordered (LPSO) phase in the $\alpha$-Mg matrix of the alloy WZ21.
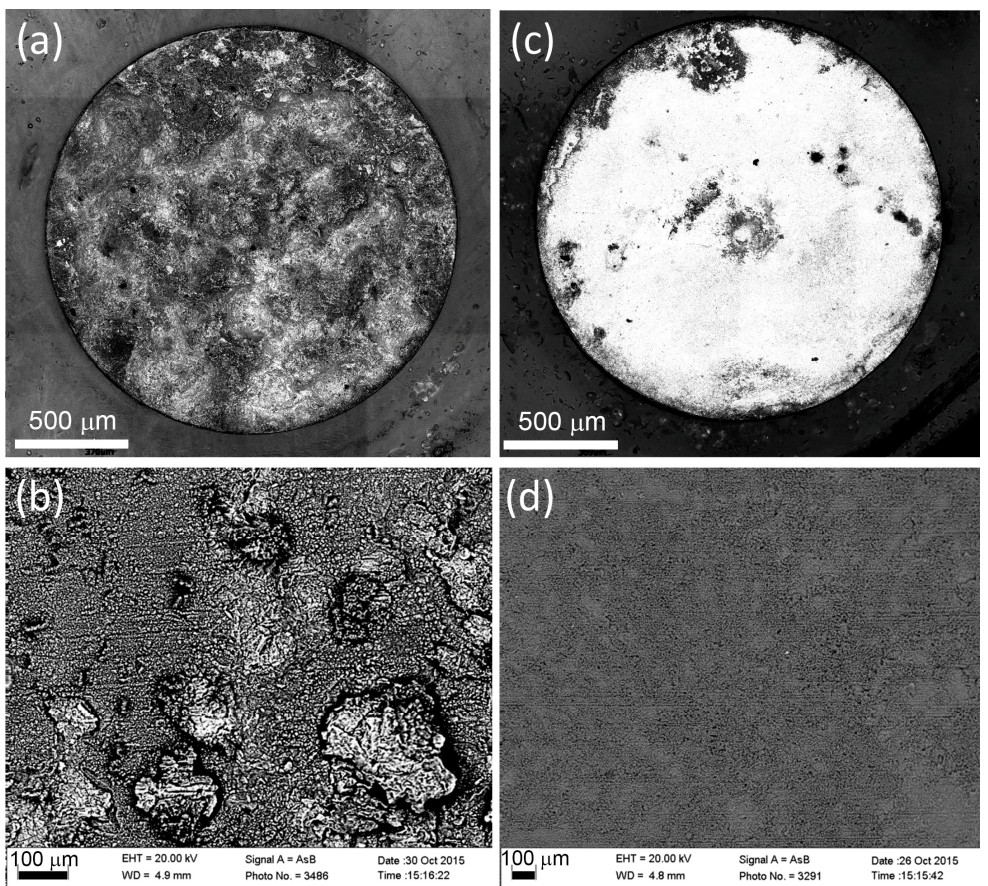

Figure 4. Microscopy images showing the surface morphology of the $\mathrm{Mg}$ alloy specimens after corrosion testing in the $0.9 \% \mathrm{NaCl}$ solution for $24 \mathrm{~h}$ : (a,b) ZK60, (c,d) WZ21; (a,c) optical view, (b,d) SEM images. Corrosion products were removed before observation.

Figure 5 summarizes the results of fatigue tests in air and $\mathrm{NaCl}$ solution for differently processed high strength ZK60 alloy and high-performance alloy WZ21. One can see that all of the alloys demonstrate reasonably good fatigue properties in the high cyclic region in ambient air (c.f. fatigue limit under symmetrical push-pull loading, $\sigma_{-1}$ ), Table 1 , comparable or higher than those typical of their conventionally manufactured counterparts [28]. However, the fatigue endurance drops sharply when the same materials were tested in the $\mathrm{NaCl}$ solution. Data for the hot extruded reference ZK60 alloy are shown for comparison. One can notice that MIF improves the fatigue life significantly. Furthermore, the alloy with the finer and more homogeneous microstructure after two-step processing at $400{ }^{\circ} \mathrm{C}$ and $300{ }^{\circ} \mathrm{C}$ has notably longer fatigue life than the same alloy after one-step MIF or the alloy WZ21. Regardless of the differences in their microstructural states, chemical composition, distribution of second phases, and even regardless of the notably different static corrosion behavior, all of the materials broke at $10^{6}$ cycles at the stress amplitude about $25-30 \mathrm{MPa}$, which is a quite low value for the fatigue limit. 


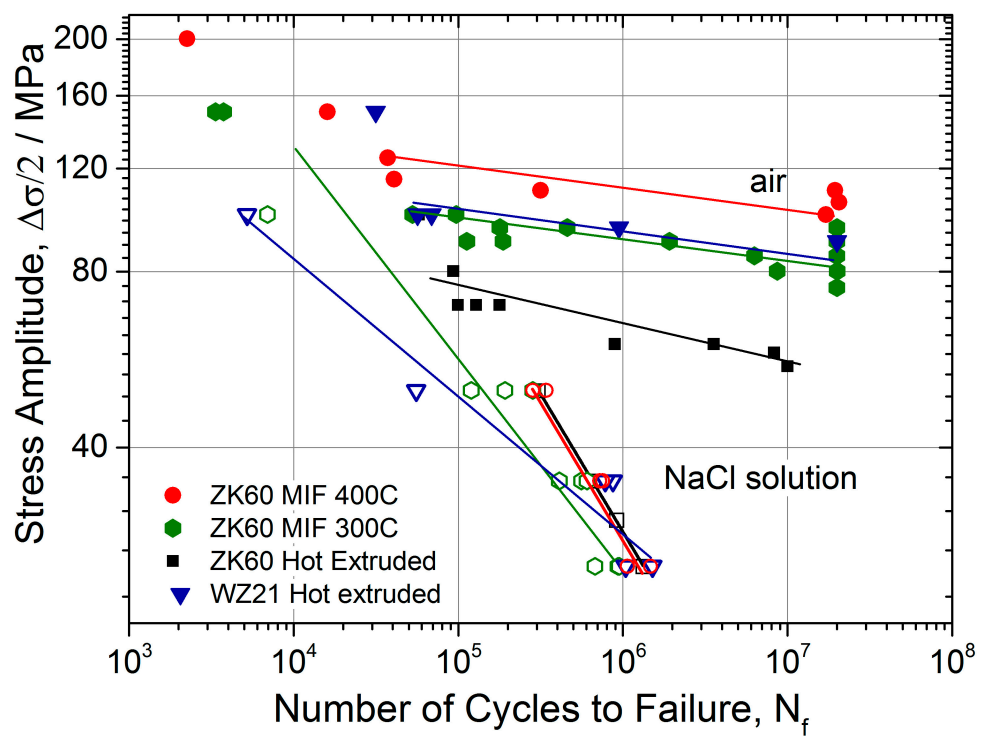

Figure 5. Fatigue life (S-N) diagram for the ZK60 alloys after different processing and alloy WZ21 in air and $0.9 \% \mathrm{NaCl}$ solution (filed symbols refer to the tests in dry air while open symbols of the same shape and color represent the results of the tests in $0.9 \% \mathrm{NaCl}$ solution).

The corrosion rate is known to be larger for alloys with a larger volume fraction of the LPSO phase because the $\alpha-\mathrm{Mg}$ phase around the LPSO phase experiences pitting corrosion, thus favoring galvanic corrosion [11]. Among many other alloys in the class of the LPSO alloys, the alloys of the Mg-2Y-1Zn composition (including WZ21) exhibit the lowest corrosion rate due to the relatively low fraction of the relatively homogeneously distributed $\mathrm{Mg}_{12} \mathrm{YZn}$ phase [29]. In comparison with other $\mathrm{Mg}$ alloys, such as ZK60, the alloys with the LPSO structure exhibit usually a smaller biodegradation rate [30]. This is confirmed in the present work by measuring the general corrosion rate, which appeared to be appreciably smaller than that for other materials tested in $\mathrm{NaCl}$ solution, Table 1 (see also Figure 5). However, as opposes to our expectations, the alloy WZ21 does not show a better fatigue performance in the physiological solution.

Figure 6 shows typical fracture surface morphology after corrosion fatigue of the two-step MIF-processed ZK60 alloy tested at $\Delta \sigma / 2=50 \mathrm{MPa}$. The surface appearance of other alloys tested, despite the differences in their microstructure, does not differ considerably from the example illustrated in Figure 6. Hence, the most important observation is that the collective effect of the aggressive environment and the cyclic stress causes the accelerated material's loss rate and the significant roughening of the surface exposed to the corrosive agent. As an immediate consequence of this effect, the local stress risers form on the surface of the fatigued specimen. During corrosion fatigue, the local damage (corrosive groves, pits, and cracks) propagates quickly inside the specimen, resulting in the increasing influence of mechanical factors, such as notch sensitivity, stress concentration, and intensity in fatigue development, while the significance of the microstructural factors reduces. It seems evident that the thin native oxide hydroxide film on the surface does not provide resistance to corrosive agents to the desired extent under cyclic stresses. The pre-existing or newly formed passive layer is not stable in aqueous solution containing chloride. It breaks easily under the alternating stress; the surface is exposed to the aggressive environment and local corrosion occurs. 


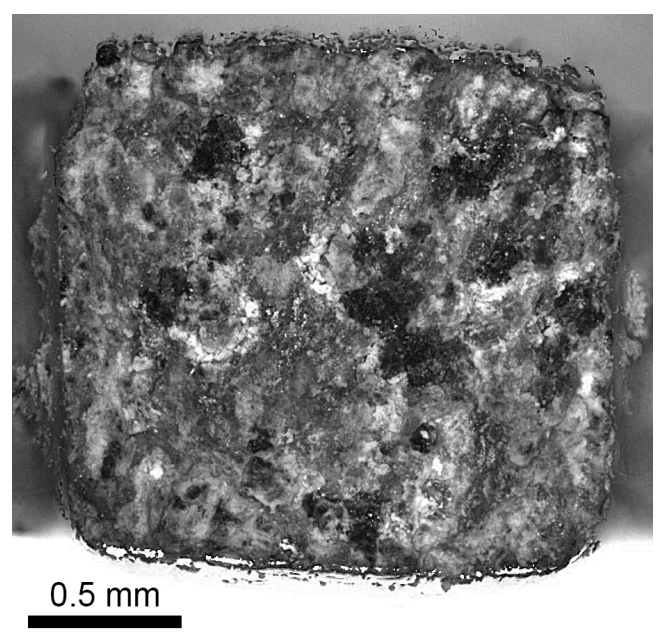

Figure 6. Laser confocal image microscopy image showing typical fracture surface morphology appearance after corrosion fatigue of the two-step MIF-processed ZK60 alloy tested at $\Delta \sigma / 2=50 \mathrm{MPa}$.

\section{Conclusions}

The negative message being delivered in the present brief communication is that the corrosion fatigue resistance of magnesium alloys, even of fine-grained high strength alloys and the alloy with the LPSO phase, is still far from being satisfactory for prospective applications. Accelerated environmentally assisted degradation under cyclic loading is associated with poor protective capacity of the passive layer on the magnesium surface. Despite the discouraging nature of this result, we would like to underline that the capability of modern methods for magnesium alloy design against corrosion fatigue has been explored to a very little extent as yet.

As noticed by Ghali et al. [31], with regard to the general corrosion in Mg alloys, lower than desired corrosion resistance is most of the time due to poor design, contamination, galvanic couples, and/or inadequate surface protection schemes for specific applications. The same conclusion seems to be applicable to the corrosion fatigue, which requires additional thoughtful consideration of several influencing factors such as cyclic frequency (it is usually irrelevant in fatigue studies in air but it becomes very significant in corrosive media; the effect is of particular importance for bio-medical applications where the loading spectrum in vivo may differ substantially from that used in vitro), stress corrosion cracking, loading conditions (the design for low- and high-cycle fatigue may be significantly dissimilar), control of the surface microstructure, etc.

Acknowledgments: The support from the Ministry of Education and Science of RF through the State Assignment according to the contract No. 11.5281.2017/8.9 is gratefully appreciated. Special thanks go to R. Matsumoto and M. Yamasaki (Kumamoto University, Japan) for their skillful help with TEM observations.

Author Contributions: All co-authors have contributed substantially to the paper. Alexei Vinogradov devised the experiments and wrote the paper, Mikhail Linderov and Evgenii Vasilev performed the experiments, Mikhail Markushev processed the materials by SPD and discussed the results, Dmitry Merson designed the experiments and discussed the results.

Conflicts of Interest: The authors declare no conflict of interest.

\section{References}

1. Stephens, R.I.; Schrader, C.D.; Lease, K.B. Corrosion fatigue of AZ91E-T6 cast magnesium alloy in a 3.5 percent $\mathrm{NaCl}$ aqueous environment. J. Eng. Mater. Technol. Trans. ASME 1995, 117, 293-298. [CrossRef]

2. Eliezer, A.; Gutman, E.M.; Abramov, E.; Unigovski, Y. Corrosion fatigue of die-cast and extruded magnesium alloys. J. Light Met. 2001, 1, 179-186. [CrossRef]

3. Gutman, E.M.; Eliezer, A.; Unigovski, Y.; Abramov, E. Corrosion fatigue of magnesium alloys. In Materials Science Forum; Trans Tech Publications: Zürich, Switzerland, 2003; Volume 419-422, pp. 115-120. 
4. Wittke, P.; Klein, M.; Dieringa, H.; Walther, F. Corrosion fatigue assessment of creep-resistant magnesium alloy Mg-4Al-2Ba-2Ca in aqueous sodium chloride solution. Int. J. Fatigue 2016, 83 Pt 1, 59-65. [CrossRef]

5. Uematsu, Y.; Tokaji, K.; Ohashi, T. Corrosion fatigue behavior of extruded AZ80, AZ61 and AM60 magnesium alloys in distilled water. Strength Mater. 2008, 40, 130-133. [CrossRef]

6. Bhuiyan, M.S.; Mutoh, Y.; Murai, T.; Iwakami, S. Corrosion fatigue behavior of extruded magnesium alloy AZ61 under three different corrosive environments. Int. J. Fatigue 2008, 30, 1756-1765. [CrossRef]

7. Unigovski, Y.; Eliezer, A.; Abramov, E.; Snir, Y.; Gutman, E.M. Corrosion fatigue of extruded magnesium alloys. Mater. Sci. Eng. A 2003, 360, 132-139. [CrossRef]

8. Hilpert, M.; Wagner, L. Corrosion fatigue behavior of the high-strength magnesium alloy AZ80. J. Mater. Eng. Perform. 2000, 9, 402-407. [CrossRef]

9. Witte, F. The history of biodegradable magnesium implants: A review. Acta Biomater. 2010, 6, 1680-1692. [CrossRef] [PubMed]

10. Witte, F.; Hort, N.; Vogt, C.; Cohen, S.; Kainer, K.U.; Willumeit, R.; Feyerabend, F. Degradable biomaterials based on magnesium corrosion. Curr. Opin. Solid State Mater. Sci. 2008, 12, 63-72. [CrossRef]

11. Li, X.; Liu, X.; Wu, S.; Yeung, K.W.K.; Zheng, Y.; Chu, P.K. Design of magnesium alloys with controllable degradation for biomedical implants: From bulk to surface. Acta Biomater. 2016, 45, 2-30. [CrossRef] [PubMed]

12. Antunes, R.A.; de Oliveira, M.C.L. Corrosion fatigue of biomedical metallic alloys: Mechanisms and mitigation. Acta Biomater. 2012, 8, 937-962. [CrossRef] [PubMed]

13. Gu, X.N.; Zhou, W.R.; Zheng, Y.F.; Cheng, Y.; Wei, S.C.; Zhong, S.P.; Xi, T.F.; Chen, L.J. Corrosion fatigue behaviors of two biomedical mg alloys-AZ91d and WE43-in simulated body fluid. Acta Biomater. 2010, 6, 4605-4613. [CrossRef] [PubMed]

14. Estrin, Y.; Vinogradov, A. Extreme grain refinement by severe plastic deformation: A wealth of challenging science. Acta Mater. 2013, 61, 782-817. [CrossRef]

15. Miyamoto, H.; Harada, K.; Mimaki, T.; Vinogradov, A.; Hashimoto, S. Corrosion of ultra-fine grained copper fabricated by equal-channel angular pressing. Corros. Sci. 2008, 50, 1215-1220. [CrossRef]

16. Yamasaki, T.; Miyamoto, H.; Mimaki, T.; Vinogradov, A.; Hashimoto, S. Stress corrosion cracking susceptibility of ultra-fine grain copper produced by equal-channel angular pressing. Mater. Sci. Eng. A 2001, 318, 122-128. [CrossRef]

17. Aung, N.N.; Zhou, W. Effect of grain size and twins on corrosion behaviour of AZ31B magnesium alloy. Corros. Sci. 2010, 52, 589-594. [CrossRef]

18. Vinogradov, A.; Orlov, D.; Estrin, Y. Improvement of fatigue strength of a Mg-Zn-Zr alloy by integrated extrusion and equal-channel angular pressing. Scr. Mater. 2012, 67, 209-212. [CrossRef]

19. Orlov, D.; Raab, G.; Lamark, T.T.; Popov, M.; Estrin, Y. Improvement of mechanical properties of magnesium alloy ZK60 by integrated extrusion and equal channel angular pressing. Acta Mater. 2011, 59, 375-385. [CrossRef]

20. Orlov, D.; Ralston, K.D.; Birbilis, N.; Estrin, Y. Enhanced corrosion resistance of mg alloy ZK60 after processing by integrated extrusion and equal channel angular pressing. Acta Mater. 2011, 59, 6176-6186. [CrossRef]

21. Nugmanov, D.R.; Sitdikov, O.S.; Markushev, M.V. Microstructure evolution in ma14 magnesium alloy under multi-step isothermal forging. Lett. Mater. 2011, 1, 213-216. [CrossRef]

22. Vasilev, E.; Linderov, M.; Nugmanov, D.; Sitdikov, O.; Markushev, M.; Vinogradov, A. Fatigue performance of mg-zn-zr alloy processed by hot severe plastic deformation. Metals 2015, 5, 2316-2327. [CrossRef]

23. Merson, D.V.E.; Markushev, M.; Vinogradov, A. On the corrosion of magnesium zk60 alloy after severe plastic deformation. Lett. Mater. 2017, 7, 421-427. [CrossRef]

24. Abe, E.; Kawamura, Y.; Hayashi, K.; Inoue, A. Long-period ordered structure in a high-strength nanocrystalline Mg-1 at \%Zn-2 at \%Y alloy studied by atomic-resolution z-contrast stem. Acta Mater. 2002, 50, 3845-3857. [CrossRef]

25. Kawamura, Y.; Yamasaki, M. Formation and mechanical properties of Mg97Zn1Re 2 alloys with long-period stacking ordered structure. Mater. Trans. 2007, 48, 2986-2992. [CrossRef]

26. Xu, D.; Han, E.H.; Xu, Y. Effect of long-period stacking ordered phase on microstructure, mechanical property and corrosion resistance of mg alloys: A review. Prog. Nat. Sci. Mater. Int. 2016, 26, 117-128. [CrossRef] 
27. Nugmanov, D.; Sitdikov, O.; Markushev, M. Grain refinement in the magnesium alloy ZK60 during multi-step isothermal forging. Mater. Sci. Forum 2015, 830-831, 7-10. [CrossRef]

28. Liu, W.; Dong, J.; Zhang, P.; Yao, Z.; Zhai, C.; Ding, W. High cycle fatigue behavior of as-extruded ZK60 magnesium alloy. J. Mater. Sci. 2009, 44, 2916-2924. [CrossRef]

29. Zhang, J.; Xu, J.; Cheng, W.; Chen, C.; Kang, J. Corrosion behavior of Mg-Zn-Y alloy with long-period stacking ordered structures. J. Mater. Sci. Technol. 2012, 28, 1157-1162. [CrossRef]

30. Zhao, X.; Shi, L.-L.; Xu, J. Mg-Zn-Y alloys with long-period stacking ordered structure: In vitro assessments of biodegradation behavior. Mater. Sci. Eng. C 2013, 33, 3627-3637. [CrossRef] [PubMed]

31. Ghali, E.; Dietzel, W.; Kainer, K.-U. General and localized corrosion of magnesium alloys: A critical review. J. Mater. Eng. Perform. 2004, 13, 7-23. [CrossRef]

(c) 2017 by the authors. Licensee MDPI, Basel, Switzerland. This article is an open access article distributed under the terms and conditions of the Creative Commons Attribution (CC BY) license (http://creativecommons.org/licenses/by/4.0/). 